\title{
Peripheral Blood Flow and Oxygen Extraction in the Sick, Newborn Very Low Birth Weight Infant Shortly After Birth
}

\author{
CHRISTOPHER M. KISSACK AND A. MICHAEL WEINDLING
}

The Simpson Centre for Reproductive Health [C.M.K.], Royal Infirmary of Edinburgh, Edinburgh, EH16 4SA, United Kingdom; School of Reproductive and Developmental Medicine [A.M.W.], University of Liverpool, Liverpool, L8 7SS, United Kingdom

\begin{abstract}
This study examined the relationship between blood pressure, peripheral blood flow (PBF), and peripheral fractional oxygen extraction (FOE). Variables that may influence PBF and peripheral FOE were also measured. Measurements of PBF by near infrared spectroscopy and fractional shortening by echocardiography were made within $12 \mathrm{~h}$ of birth in 24 infants less than 32 wk gestation. Blood gases, $\mathrm{Hb}$, temperature, and blood pressure were also measured. PBF was significantly correlated with fractional shortening $(r=0.56, p=0.005), \mathrm{Po}_{2}(r=-0.5, p=$ $0.01)$, and peripheral temperature $(r=0.52, p=0.01)$. Peripheral FOE was significantly correlated with fractional shortening $(r=$ $-0.48, p=0.02), \mathrm{Po}_{2}(r=0.52, p=0.02)$, and $\mathrm{PCO}_{2}(r=-0.53$, $p=0.008)$, but not with peripheral temperature. There was no significant correlation between blood pressure and either PBF or peripheral FOE. These results indicate the importance of several physiologic variables, but not blood pressure, in determining peripheral tissue oxygen delivery in sick preterm infants receiving intensive care. It adds weight to the idea that blood pressure should not be considered a surrogate for peripheral blood flow and oxygen delivery. (Pediatr Res 65: 462-467, 2009)
\end{abstract}

A dequate blood flow and oxygen delivery to the peripheral tissues of a sick, newborn infant is a sine qua non of neonatal intensive care. The adequacy of tissue oxygen delivery is difficult to measure directly, and thus it is usual to measure surrogate variables that may be related to tissue oxygen availability and are more amenable to continuous monitoring, such as arterial oxygen saturation and arterial blood pressure.

Peripheral oxygen delivery is determined by peripheral blood flow (PBF) and arterial oxygen content. PBF is related to vascular resistance and blood pressure, which in turn depends on cardiac function; arterial oxygen content depends on the blood $\mathrm{Hb}$ concentration and arterial $\mathrm{Po}_{2}$.

As blood flow is related to vascular resistance and blood pressure, there are a number of other factors that may influence blood flow and thus oxygen delivery to the peripheral tissues. These include blood gases, peripheral temperature, arterial $\mathrm{Hb}$ concentration, and cardiac function. During the first few hours after birth, which is a period of great instability for the critically ill preterm infant when blood pressure, left

Received May 7, 2008; accepted November 11, 2008

Correspondence: Christopher M. Kissack, M.D., Neonatal Unit, The Simpson Centre for Reproductive Health, Royal Infirmary of Edinburgh, 51 Little France Road, Edinburgh, EH34 5HJ, United Kingdom; e-mail: chris.kissack@luht.nhs.scot.uk

Supported by the NHS Research and Development Executive, Action Research, and the Newborn Appeal. ventricular output and systemic blood flow are all low (1-3), $\mathrm{PBF}$ and thus oxygen delivery may be inadequate.

Peripheral fractional oxygen extraction (FOE), the ratio of oxygen consumption to oxygen delivery (4), gives information on the adequacy of tissue oxygenation. Raised FOE most likely represents decreased oxygen delivery, which may be due to reduced blood flow (poor perfusion) or reduced arterial oxygen content (hypoxaemia).

This study explored the relationships between physiologic variables and both PBF and peripheral FOE during the first $12 \mathrm{~h}$ after birth in a group of sick, ventilated, very low birth weight infants. The hypothesis tested was that PBF and peripheral FOE were correlated with mean arterial blood pressure.

\section{METHODS AND SUBJECTS}

The study was approved by the Liverpool Children's Regional Ethics Committee. Informed consent was obtained from the parents before making any measurements. ${ }^{1}$

All infants were delivered at less than 32 wk of gestation and were of birth weight below $1500 \mathrm{~g}$. All infants had an umbilical arterial catheter for continuous blood pressure monitoring and intermittent blood sampling, and were receiving conventional mechanical ventilation. During the period over which this study was carried out there were 26 consecutive admissions to the neonatal intensive care unit of infants meeting all the eligibility criteria; of these two parents refused consent and therefore 24 infants were studied. All measurements were made within the first $12 \mathrm{~h}$ after birth.

$\boldsymbol{P B F}$ and $\boldsymbol{F O E}$ measurement. Both $\mathrm{PBF}$ and peripheral FOE were measured using a complete peripheral venous occlusion technique, with measurement of changes in oxygenated and deoxygenated $\mathrm{Hb}$ ( $\mathrm{HbO}$ and $\mathrm{Hb}$ ) concentration made using near infrared spectroscopy (Hammamatsu NIRO 500, Hammamatsu UK). Transmitting and receiving near infrared optodes were secured to the anterior and posterior aspects of the upper part of the right forearm, and the inter-optode distance was measured using calipers. All inter-optode distances were between 1.0 and $1.5 \mathrm{~cm}$, the distance being limited by the size of the forearm. The differential path length factor used was 3.59, a figure generated by time of flight measurement of the adult forearm (5). Light was excluded using an occlusive blanket. The near infrared spectroscope locked in a set level of laser activity, which resulted in an arbitrary baseline, against which relative changes could be measured. The spectroscope recorded the quantity of near infrared photons reaching the receiving optode every $0.5 \mathrm{~s}$. The arterial oxygen saturation was measured using a pulse oximeter (Datex, Finland), with the probe located on the right hand. The pulse oximeter generated a saturation reading every $0.5 \mathrm{~s}$ at the same time as measurements were made by the near infrared spectroscope. Both the oximetry and near infrared data were collected in real-time and stored on a laptop
Abbreviations: FOE, fractional oxygen extraction; HbO, oxyhaemoglobin; HbT, total haemoglobin; LVEDD, ventricular diameter at the end of diastole; $\mathbf{P a C O}_{2}$, arterial partial pressure of carbon dioxide; $\mathbf{P a O}$, arterial partial pressure of oxygen; PBF, peripheral blood flow; $\mathbf{S a o}_{2}$, arterial oxygen haemoglobin saturation; $\mathbf{S v o}_{2}$, venous oxygen haemoglobin saturation 
computer for later analysis. The mean arterial oxygen $\mathrm{Hb}$ saturation $\left(\mathrm{SaO}_{2}\right)$ for the $5 \mathrm{~s}$ immediately preceding the peripheral venous occlusion was taken as the value for $\mathrm{SaO}_{2}$.

Once the infant was settled, after $5 \mathrm{~s}$ to obtain a suitably steady baseline, a peripheral venous occlusion was performed using a sphygmomanometer cuff inflated to below diastolic arterial blood pressure. The typical mean central venous pressure in very low birth weight infants is $5 \mathrm{~mm} \mathrm{Hg} \mathrm{(6),} \mathrm{and}$ a cuff pressure of $10 \mathrm{~mm} \mathrm{Hg}$ was sufficient. Inadvertent arterial occlusion was avoided by observing the spectroscope signal, the invasive diastolic blood pressure value, and the saturation wave form. Five measurements, taken consecutively once steady baseline was again achieved, were made.

$\mathrm{PBF}$ was calculated from peripheral $\mathrm{Hb}$ flow, measured using near infrared spectroscopy. The total venous occlusion caused pooling of venous blood and a consequent rise in the amount of venous $\mathrm{Hb}$ present in the field of study. The change in total $\mathrm{Hb}(\mathrm{HbT})$, which is the sum of the changes in oxygenated and deoxygenated $\mathrm{Hb}$ as measured by spectroscopy, is related to peripheral $\mathrm{Hb}$ flow as follows:

$$
\mathrm{PHbF}=\Delta \mathrm{HbT} / t
$$

where $\mathrm{PHbF}$ is peripheral $\mathrm{Hb}$ flow, $\Delta \mathrm{HbT}$ is the change in total (oxygenated + deoxygenated) $\mathrm{Hb}$, and $t$ is the elapsed time.

Peripheral $\mathrm{Hb}$ flow was determined from the slope of the line that resulted from plotting $\Delta \mathrm{HbT}$ against time. The mean of the five measurements was taken as the final value. This technique has been compared with measurement of $\mathrm{Hb}$ flow by plethysmography in human adults, with good correlation $(r=$ $0.94)$ between the two methods (7).

$\mathrm{PBF}$ was then calculated from the peripheral $\mathrm{Hb}$ flow data as follows:

$$
\mathrm{PBF}=0.0645 \times \mathrm{PHbF} / \mathrm{Hb}
$$

where PBF is peripheral blood flow. The calculation of PBF involves a constant (0.0645), which incorporates the molecular weight of $\mathrm{Hb}$ and conversion into $\mathrm{mL} / 100 \mathrm{~mL} / \mathrm{min}$. $\mathrm{PHbF}$ is peripheral $\mathrm{Hb}$ flow, measured by near infrared spectroscopy, measured in $\mu \mathrm{mol} / 100 \mathrm{~mL} / \mathrm{min}$. $\mathrm{Hb}$ is arterial $\mathrm{Hb}$ concentration, determined by laboratory analysis, measured in $\mathrm{g} / \mathrm{dL}$.

Peripheral FOE was calculated from peripheral venous saturation, which was also measured using the complete peripheral venous occlusion technique. For each of the 10 subsequent half-second intervals immediately after the venous occlusion, the change in oxygenated $\mathrm{Hb}(\Delta \mathrm{HbO})$ and deoxygenated $\mathrm{Hb}(\Delta \mathrm{Hb})$ that resulted from the pooling of venous blood was calculated. This technique has been shown to be preferable to using $\Delta \mathrm{HbO}$ and $\Delta \mathrm{Hb}$ at the peak of the curve, or to calculating area under the curve (8). Measurements were only accepted if there was a preceding steady baseline for both oxygenated and deoxygenated $\mathrm{Hb}$, followed by a rise in both during the venous occlusion, with both returning to the preexisting baseline immediately after the compression. The mean of 10 readings of $\Delta \mathrm{HbO}$ and $\Delta \mathrm{Hb}$ were used to calculate peripheral venous saturation, using the equation:

$$
\mathrm{SvO}_{2}=\Delta \mathrm{HbO} /(\Delta \mathrm{HbO}+\Delta \mathrm{Hb})
$$

where $\mathrm{SvO}_{2}$ is the peripheral venous oxygen saturation, $\Delta \mathrm{HbO}$ is the mean change in oxygenated $\mathrm{Hb}$ over the $5 \mathrm{~s}$ after venous occlusion, and $\Delta \mathrm{Hb}$ is the mean change in deoxygenated $\mathrm{Hb}$ over the $5 \mathrm{~s}$ after venous occlusion.

As was done for PBF, the mean of the five measurements was taken as the final value of peripheral venous oxygen saturation.

Peripheral FOE was then calculated from the venous saturation data as follows:

$$
\mathrm{FOE}=\left(\mathrm{SaO}_{2}-\mathrm{SvO}_{2}\right) / \mathrm{SaO}_{2}
$$

where $\mathrm{FOE}$ is peripheral fractional oxygen extraction, $\mathrm{SaO}_{2}$ is arterial oxygen $\mathrm{Hb}$ saturation, measured at the right hand by pulse oximetry, and $\mathrm{SvO}_{2}$ is peripheral venous oxygen $\mathrm{Hb}$ saturation, measured by near infrared spectroscopy and venous occlusion.

Echocardiographic measurement of endocardial fractional shortening. The shortening fraction was measured by echocardiography (Vingmed CFM 725 ultrasound scanner, Vingmed, Norway) with a $7.5 \mathrm{MHz}$ probe (GE Ultrasound, USA). Fractional shortening was assessed by a standard technique (9), using M-mode echocardiography and a parasternal long axis window. Measurements of left ventricular diameter at the end of diastole and end of systole were made, commencing immediately after cessation of the near infrared measurements. The fractional shortening was calculated using the formula:

$$
\mathrm{FS}=(\mathrm{LVEDD}-\mathrm{LVESD}) / \mathrm{LVEDD} \times 100
$$

where FS is endocardial fractional shortening, LVEDD is left ventricular diameter at the end of diastole, and LVESD is left ventricular diameter at the end of systole.

The measurement was repeated three times, and the mean of the three readings taken as the final value for endocardial fractional shortening.

Measurement of other variables. All infants had an indwelling arterial catheter for continuous blood pressure monitoring. Arterial blood samples were taken for blood gas measurement after completion of the near infrared and echocardiographic studies. Peripheral temperature was measured using a skin probe attached to the sole of the foot.

Statistics. Data were analyzed using SPSS version 11.0.0 (SPSS, USA). Data were generally summarized as mean $\pm \mathrm{SD}$, or median (interquartile range) when the data did not demonstrate a normal distribution. Normality of data were ascertained using histogram plots and Shapiro-Wilk test. Variables tested for their relationship to PBF were blood pressure, FS, peripheral temperature, $\mathrm{PO}_{2}\left(\mathrm{PaO}_{2}\right)$, and $\mathrm{PCO}_{2}\left(\mathrm{PaCO}_{2}\right)$, but not $\mathrm{Hb}$ as this variable was used to calculate PBF. Variables tested for their relationship to peripheral FOE were blood pressure, FS, peripheral temperature, $\mathrm{PaO}_{2}, \mathrm{Hb}$, and $\mathrm{PaCO}_{2}$. Variables related to PBF and peripheral FOE were ascertained by multivariate analysis, looking for the most statistically significant model that explained most of the variation in the dependent. All variables were entered into the model, and then removed at a significance level of $p \geq 0.1$. The relationships were further examined using Pearson correlation coefficients, taking $p<0.05$ as significant.

\section{RESULTS}

Measurements. All 24 infants had successful measurements of peripheral $\mathrm{Hb}$ flow and $\mathrm{SvO}_{2}$, permitting calculation of values for PBF and peripheral FOE in all infants. Of the 24 infants, two were receiving i.v. inotropic support at the time of measurement; these infants had similar values of PBF and oxygen extraction to the other infants in the study, and they were therefore included in the analysis.

The demographic details are summarized in Table 1 The summary data for PBF, peripheral FOE and other measured variables are given in Table 2.

Multiple linear regression. Linear regression analyses to examine the determinants of PBF and peripheral FOE were performed separately.

Table 1. Demographic details for 24 infants studied

$\begin{array}{lc}\text { Gestation (w) } & 26(23-29) \\ \text { Birth weight }(\mathrm{g}) & 892(452-1358) \\ \text { Male gender } & 62 \% \\ \text { Age at time of study (h) } & 8(2-12) \\ \text { CRIB score } & 4(1-13)\end{array}$

All data are presented as median (range) except gender, which is presented as percentage of infants who were male.

CRIB, Clinical Risk Index for Babies.

Table 2. Summary results for 24 infants studied

$\begin{array}{lc}\text { Peripheral temperature }\left({ }^{\circ} \mathrm{C}\right) & 35.9 \pm 1.0 \\ \text { Endocardial fractional } & 20.8 \pm 6.6 \\ \quad \text { shortening }(\%) & \\ \begin{array}{l}\text { Mean arterial blood } \\ \text { pressure }(\mathrm{mm} \mathrm{Hg})\end{array} & 40 \pm 8 \\ \begin{array}{l}\text { Haemoglobin concentration } \\ \quad(\mathrm{g} / \mathrm{dL})\end{array} & 16.3(15.2-18.1) \\ \text { Arterial } \mathrm{PaO}_{2}(\mathrm{~mm} \mathrm{Hg}) & 53.1 \pm 12.7 \\ \text { Arterial } \mathrm{PaCO}_{2}(\mathrm{~mm} \mathrm{Hg}) & 40.0 \pm 9.0 \\ \mathrm{PFOE} & 0.27 \pm 0.06 \\ \mathrm{PBF}(\mathrm{mL} / 100 \mathrm{~mL} / \mathrm{min}) & 6.0(3.7-11.9)\end{array}$

Most data are presented as mean \pm standard deviation, except hemoglobin concentration and PBF (non-normally distributed data, presented as median with interquartile range). 
Table 3. Summary of the most significant model, as demonstrated by the significance of the $\mathrm{F}$ statistic, for determining peripheral blood flow

\begin{tabular}{|c|c|c|c|c|}
\hline \multicolumn{5}{|c|}{ Linear regression for $\mathrm{PBF}$} \\
\hline$R^{2}$ & \multicolumn{2}{|c|}{$F$ Statistic } & \multicolumn{2}{|c|}{ Significance } \\
\hline \multirow[t]{3}{*}{0.66} & \multicolumn{2}{|c|}{11.5} & \multicolumn{2}{|c|}{0.0002} \\
\hline & \multicolumn{2}{|c|}{$\begin{array}{l}\text { Unstandardized } \\
\text { coefficients }\end{array}$} & \multirow[b]{2}{*}{$t$ Statistic } & \multirow[b]{2}{*}{ Significance } \\
\hline & B & Std error & & \\
\hline Constant & -74.8 & 30.9 & -2.4 & 0.026 \\
\hline Peripheral temperature & 2.4 & 0.9 & 2.8 & 0.012 \\
\hline Fractional shortening & 0.4 & 0.1 & 3.0 & 0.007 \\
\hline $\mathrm{PaO}_{2}$ & -0.2 & 0.1 & -3.2 & 0.005 \\
\hline
\end{tabular}

The amount of variation in the dependent variable explained by the model is indicated by $R^{2}$. Variables tested for their relationship to PBF were peripheral temperature, fractional shortening, $\mathrm{PaO}_{2}, \mathrm{PaCO}_{2}$, and blood pressure. The $t$ statistics indicated that the three included variables had comparable effects in determining the variation in the dependent variable.

Table 4. Summary of the most significant model, as demonstrated by the significance of the $\mathrm{F}$ statistic, for determining peripheral FOE

\begin{tabular}{|c|c|c|c|c|}
\hline \multicolumn{5}{|c|}{ Linear regression for peripheral FOE } \\
\hline$R^{2}$ & \multicolumn{2}{|l|}{$F$ Statistic } & \multicolumn{2}{|c|}{ Significance } \\
\hline \multirow[t]{3}{*}{0.69} & \multicolumn{2}{|l|}{9.8} & \multicolumn{2}{|c|}{0.0003} \\
\hline & \multicolumn{2}{|c|}{ Unstandardized coefficients } & \multirow[b]{2}{*}{$t$ Statistic } & \multirow[b]{2}{*}{ Significance } \\
\hline & B & Std error & & \\
\hline Constant & 0.41 & 0.083 & 4.9 & 0.0001 \\
\hline Hemoglobin & -0.005 & 0.003 & -1.9 & 0.077 \\
\hline Fractional shortening & -0.003 & 0.001 & -2.2 & 0.044 \\
\hline $\mathrm{PaCO}_{2}$ & -0.003 & 0.001 & -2.6 & 0.022 \\
\hline $\mathrm{PaO}_{2}$ & 0.003 & 0.001 & 3.7 & 0.002 \\
\hline
\end{tabular}

The amount of variation in the dependent variable explained by the model is indicated by $R^{2}$. Variables tested for their relationship to peripheral FOE were $\mathrm{Hb}$, fractional shortening, $\mathrm{PaCO}_{2}, \mathrm{PaO}_{2}$, peripheral temperature, and blood pressure. The $t$ statistics indicated that the first three included variables had broadly comparable effects in determining the variation in the dependent variable, and that $\mathrm{PaO}_{2}$ had a stronger effect and operated in the opposite direction to the other three.

The best model for PBF involved only peripheral temperature, endocardial fractional shortening, and arterial $\mathrm{Po}_{2}$ $\left(\mathrm{PaO}_{2}\right)\left(R^{2}=0.66, p=0.0002\right)$. This model is summarized in Table 3.

The best model for peripheral FOE involved only endocardial fractional shortening, $\mathrm{PaO}_{2}$, arterial $\mathrm{PCO}_{2}\left(\mathrm{PaCO}_{2}\right)$ and arterial $\mathrm{Hb}$ concentration $\left(R^{2}=0.70, p=0.0003\right)$. This model is summarized in Table 4.

Mean arterial blood pressure. Blood pressure was not implicated in either multiple linear regression or bivariate analyses. The relationships between both PBF and peripheral FOE and mean arterial blood pressure are presented in Figure 1. There was no significant correlation between mean arterial blood pressure and either PBF ( $r=-0.30, n=24, p=\mathrm{NS})$ or peripheral FOE $(r=0.06, n=24, p=\mathrm{NS})$.

Endocardial fractional shortening. Endocardial fractional shortening was implicated in both multiple linear regressions. The relationships between both PBF and peripheral FOE and endocardial fractional shortening are presented in Figure 2. There was a significant positive correlation be-
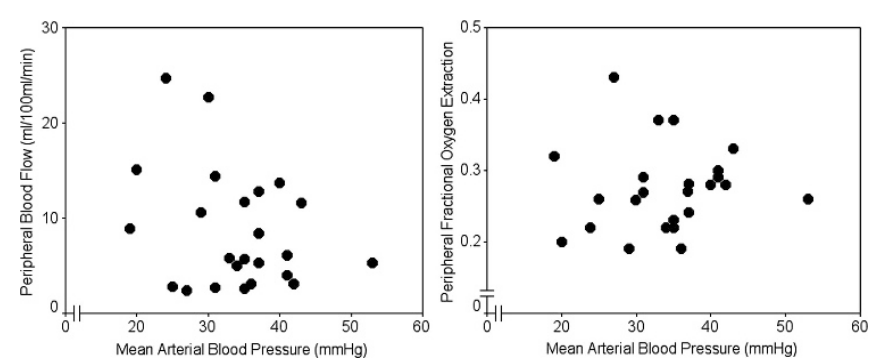

Figure 1. Peripheral blood flow and fractional oxygen extraction plotted against mean arterial blood pressure. There were no significant correlations between blood pressure and either PBF ( $r=-0.30, n=24, p=\mathrm{NS})$ or peripheral FOE $(r=0.06, n=24, p=\mathrm{NS})$.
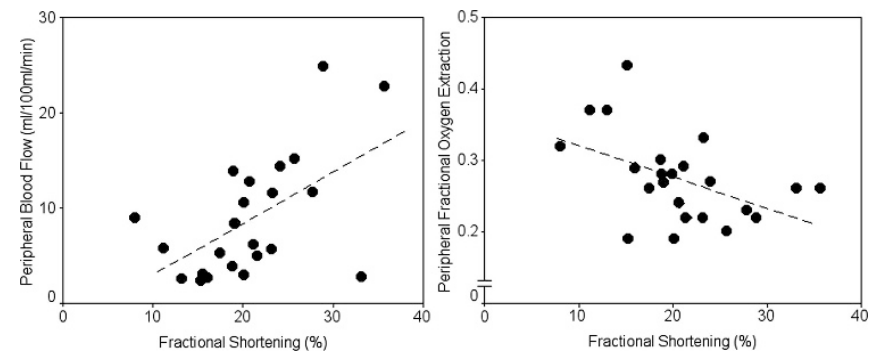

Figure 2. Peripheral blood flow and fractional oxygen extraction plotted against endocardial fractional shortening. There were significant correlations between endocardial fractional shortening and both peripheral blood flow $(r=0.56, n=23, p=0.005)$ and peripheral fractional oxygen extraction $(r=-0.48, n=23, p=0.02)$.

tween fractional shortening and $\mathrm{PBF}(r=0.56, n=23, p=$ $0.005)$, and a significant negative correlation between fractional shortening and peripheral FOE $(r=-0.48, n=23$, $p=0.02$ ).

Blood gases: $\mathrm{PaCO}_{2}$ and $\mathrm{PaO}_{2}$. Blood gases were implicated in both multiple linear regressions. The relationships between both PBF and peripheral FOE and $\mathrm{PaCO}_{2}$ are presented in Figure 3. There was no significant correlation between $\mathrm{PaCO}_{2}$ and $\mathrm{PBF}$ ( $r=0.15, n=24, p=\mathrm{NS}$ ), although there was a significant negative correlation between $\mathrm{PacO}_{2}$ and peripheral FOE $(r=-0.53, n=24, p=0.008)$.

The relationships between both PBF and peripheral FOE and $\mathrm{PaO}_{2}$ are presented in Figure 4. There was a significant negative correlation between $\mathrm{PBF}$ and $\mathrm{PaO}_{2}(r=-0.50, n=$ $24, p=0.01)$ and a significant positive correlation between peripheral FOE and $\mathrm{PaO}_{2}(r=0.52, n=24, p=0.02)$.
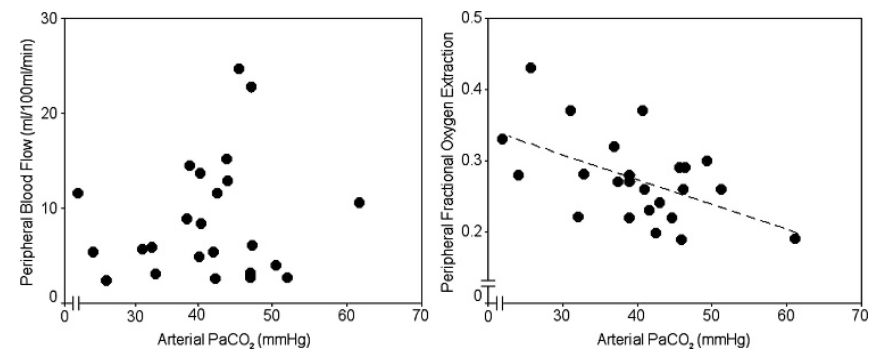

Figure 3. Peripheral blood flow and fractional oxygen extraction plotted against arterial $\mathrm{PCO}_{2}\left(\mathrm{PaCO}_{2}\right)$. There was a significant correlation between $\mathrm{PaCO}_{2}$ and peripheral fractional oxygen extraction $(r=-0.53, n=24, p=$ 0.008), but not between $\mathrm{PaCO}_{2}$ and peripheral blood flow $(r=0.15, n=24$, $p=\mathrm{NS})$. 

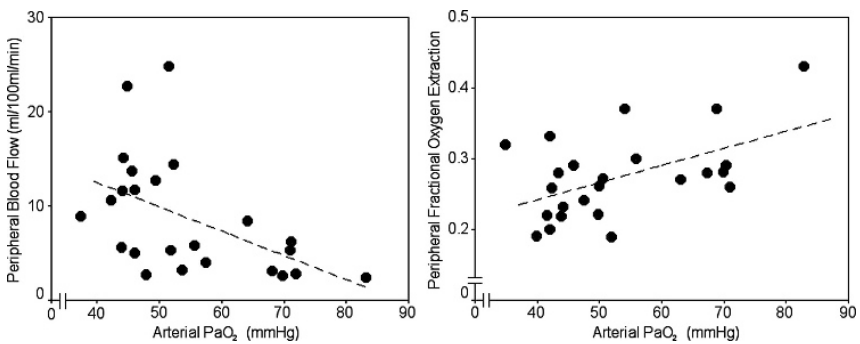

Figure 4. Peripheral blood flow and fractional oxygen extraction plotted against arterial $\mathrm{PO}_{2}$. There were significant correlations between $\mathrm{PaO}_{2}$ and both peripheral blood flow $(r=-0.50, n=24, p=0.01)$ and peripheral fractional oxygen extraction $(r=0.52, n=24, p=0.02)$.
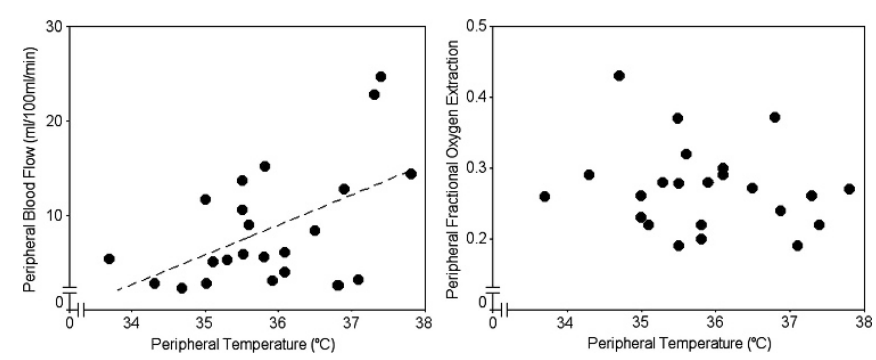

Figure 5. Peripheral blood flow and fractional oxygen extraction plotted against peripheral temperature. There was a significant correlation between peripheral temperature and peripheral blood flow $(r=0.52, n=23, p=$ 0.01 , but not between peripheral temperature and peripheral fractional oxygen extraction $(r=-0.18, n=23, p=\mathrm{NS})$.

Peripheral temperature. Temperature was implicated in the analysis to determine the variables influencing PBF. The relationships between both PBF and peripheral FOE and peripheral temperature are presented in Figure 5. There was a significant positive correlation between peripheral temperature and PBF $(r=0.52, n=23, p=0.01)$, but no significant correlation between peripheral temperature and peripheral FOE $(r=-0.18 . n=23, p=\mathrm{NS})$.

Arterial Hb concentration. The Hb concentration was implicated in the analysis to determine the variables influencing peripheral FOE. It was not included in the analysis to determine the variables influencing PBF. There was no significant correlation between either PBF or peripheral FOE and arterial $\mathrm{Hb}$ concentration.

\section{DISCUSSION}

The principal aim of this study was to examine the relationship between mean arterial blood pressure and two measures of perfusion and oxygenation in the peripheral tissues, these being PBF and FOE. In addition, other variables that may potentially influence PBF and peripheral FOE were also studied.

In this group of 24 sick, ventilated, very low birth weight preterm infants, there was no relationship between mean arterial blood pressure and either PBF or peripheral FOE (Fig. 1) during the first few hours after birth. It is noteworthy that there was a significant association between fractional shortening and both PBF and peripheral FOE. It is likely that these findings reflect the relationship between blood pressure, blood flow, and vascular resistance. Vascular resistance is increased by peripheral vasoconstriction, which is an important physiologic mechanism for the maintenance of arterial blood pressure and central blood flow to essential organs such as the brain and heart in a variety of situations, such as low cardiac output. Vasoconstriction would cause reduced PBF and oxygen delivery, which are detectable using near infrared spectroscopy. Hence, variables related to cardiac output, such as fractional shortening, would be expected to demonstrate a positive correlation with $\mathrm{PBF}$, as demonstrated in this group of infants (Fig. 2).

When PBF is decreased there will naturally follow a reduction in peripheral oxygen delivery. If the peripheral tissue metabolic rate and thus oxygen consumption is preserved in the face of reduced PBF, there must be a corresponding increase in peripheral FOE. In this case, there would be a negative correlation between fractional shortening and peripheral FOE, as demonstrated in this group (Fig. 2).

Although in this study fractional shortening was used as a measure of cardiac function, this method has its limitations. The circulation of the newborn infant undergoes a transition from right to left ventricular dominance during the days after birth. Right and left ventricular outputs change significantly during this period, and left ventricular output is affected by ductal shunting $(3,10)$. During this time fractional shortening does not change significantly suggesting that adaptive changes and the reduction in ductal shunt have less of an effect on this measurement than on others, such as measurements of cardiac output. Nevertheless, fractional shortening is influenced by preload and afterload, and may thus be influenced by other aspects of neonatal intensive care, such as fluid management, inotropes or ventilation strategies. Some, but not all, of these problems would have been circumvented by an alternative assessment of cardiac function or systemic blood flow, such as right ventricular output or superior vena cava flow $(3,11)$.

Variables other than fractional shortening also demonstrated significant associations with PBF and peripheral FOE, e.g. blood gases as shown in Figures 3 and 4. There was a strong negative correlation between $\mathrm{PaCO}_{2}$ and peripheral FOE (Fig. 3). A likely explanation is through the potent vasodilating effect of $\mathrm{PaCO}_{2}$. This effect has been demonstrated in both the cerebral and peripheral circulations of animals and humans (12-14), and it seems to operate even in the very immature human. This explanation implies that peripheral FOE decreased with increased $\mathrm{PaCO}_{2}$ because of increased peripheral oxygen delivery, a likely consequence of increased blood flow because of vasodilatation.

An unexpected finding was that there was no relationship between $\mathrm{PaCO}_{2}$ and PBF (Fig. 3). Inspection of the two panels of Figure 3 shows that some infants with higher values of $\mathrm{PaCO}_{2}$ had low rather than high blood flow, despite the fact that all infants with higher values of $\mathrm{PaCO}_{2}$ had lower levels of peripheral FOE. This suggested that increased blood flow, and consequent increased oxygen delivery, was not the explanation for the low peripheral FOE observed in these infants. As peripheral FOE is the ratio of oxygen consumption to oxygen delivery, the low peripheral FOE in these infants may have been due to reduced oxygen consumption rather than to increased blood flow and oxygen delivery in at least some of 
the infants. The negative correlation between $\mathrm{PaCO}_{2}$ and peripheral $\mathrm{FOE}$, in the absence of any demonstrated relationship between $\mathrm{PaCO}_{2}$ and $\mathrm{PBF}$, implies that $\mathrm{PaCO}_{2}$ and peripheral oxygen consumption were directly related.

It has long been known that active hyperventilation increases the total body consumption of oxygen in animals, even in passively hyperventilated dogs where there is no increase in the work of breathing $(15,16)$. This relationship also exists in humans, as demonstrated by measurements in adults undergoing cardiopulmonary bypass, which indicated that increased $\mathrm{PaCO}_{2}$ had an inverse effect upon the oxygen consumption of peripheral tissues (17). This negative correlation has also been demonstrated in a study of peripheral oxygen consumption in ventilated infants recovering from cardiac surgery (18).

There are two possible mechanisms for the relationship between $\mathrm{PaCO}_{2}$ and oxygen consumption that we have demonstrated. First, there may be a direct effect of carbon dioxide on utilization of oxygen at the cellular level. It might be that high $\mathrm{PaCO}_{2}$ levels in this group of sick infants caused cellular acidosis with consequently diminished metabolism and decreased oxygen consumption. Second, it is also plausible that there was redistribution of blood flow to other vascular beds. As there was no significant correlation between $\mathrm{PacO}_{2}$ and PBF this second explanation cannot be solely responsible for our findings, but it remains possible that altered blood flow played some part.

The effect of $\mathrm{PaO}_{2}$ was more consistent than that of $\mathrm{PaCO}_{2}$ (Fig. 4). There was a significant negative correlation between $\mathrm{PaO}_{2}$ and $\mathrm{PBF}$, suggesting that infants with high $\mathrm{PaO}_{2}$ have reduced peripheral perfusion, and the positive correlation between $\mathrm{PaO}_{2}$ and peripheral FOE would be in keeping with this. This finding is in keeping with known data concerning the responsiveness of vascular beds to $\mathrm{PaO}_{2}$; oxygen has a potent effect on vascular tone, causing most vascular beds, such as the cerebral circulation and the ductus arteriosus, to vasoconstrict, but other vessels, notably the pulmonary vascular bed, to vasodilate. $\mathrm{PaO}_{2}$ has been proposed as a local regulator of peripheral tissue perfusion, by virtue of its direct effect on the peripheral microvasculature (19). Studies in an acute hemorrhage model in the rat have demonstrated that administration of oxygen increases peripheral vascular resistance without influencing renal or splanchnic perfusion, and improves blood pressure $(20,21)$. These findings suggest that oxygen has a marked effect on vascular tone, sufficient to produce clinically relevant changes in this rat model of hemorrhage. Our study appears to indicate that oxygen has a similar effect in the sick, immature, ventilated human infant.

The mechanism by which oxygen induces these changes is not clear. A model whereby precapillary metarterioles, vessels sensitive to changes in arterial $\mathrm{PaO}_{2}$, control the perfusion of downstream capillaries, might explain our findings. In this model, these vessels respond to an increase in $\mathrm{PaO}_{2}$ by decreasing functional capillary density by redistribution of capillary blood flow, possibly through high-flow capillaries (22). Thus, high values for $\mathrm{PaO}_{2}$ could be associated with reduced tissue blood flow at the microvascular level, and a corresponding increase in peripheral oxygen extraction, both detectable using near infrared spectroscopy, as demonstrated in this study. Nevertheless, this hypothesis does not explain the exact mechanism by which oxygen may induce vasoconstriction. One plausible mechanism involves the neutralization of nitric oxide, a potent endogenous vasodilator, by reactive oxygen species (20). Some evidence for this hypothesis comes from studies that demonstrate reduced vascular tone when levels of reactive oxygen species are reduced (23).

Peripheral temperature was also implicated in the determination of peripheral tissue oxygenation. Temperature exhibited a significant positive correlation with PBF but not peripheral FOE (Fig. 5). The relationship with PBF suggested that as the peripheries became cooler, blood flow and thus oxygen delivery would decrease. The absence of any correlation between peripheral temperature and peripheral FOE would be expected if there was a corresponding reduction in metabolic activity and thus also oxygen consumption, as described in term infants during limb cooling (24). Both oxygen consumption and oxygen delivery would be decreased, and peripheral FOE, the ratio of the two, would remain unchanged, as observed in this study. The results presented here confirm the important influence of temperature on the clinical status of sick and very immature infants.

The study also examined the effect of blood $\mathrm{Hb}$ concentration, although the analysis could not be as exhaustive as with other variables, as the formula for calculating PBF included both $\mathrm{Hb}$ flow and the arterial $\mathrm{Hb}$ concentration, and thus the inclusion of $\mathrm{Hb}$ in the multivariate analysis would have been inappropriate. Although bivariate analysis did not demonstrate a significant correlation between PBF and $\mathrm{Hb}$ concentration, when it was included in the multivariate analysis for peripheral $\mathrm{FOE}, \mathrm{Hb}$ concentration was a significant determinant. This might be expected as $\mathrm{Hb}$ has an obvious role in the delivery of oxygen.

This study has demonstrated the complexity of peripheral tissue oxygenation, with cardiac function, blood gases, $\mathrm{Hb}$, and peripheral temperature all playing a part in determining blood flow and oxygen extraction in the sick, preterm infant. Other factors such as the administration of vasoactive medications or ventilation strategy may also play a role, although these factors were not examined in this study. Clinicians need to bear this complexity in mind. Blood pressure did not appear to be important, and thus this study adds to the weight of evidence that indicates that this is a poor surrogate measurement for the adequacy of oxygen delivery to the peripheral tissues. Direct measurement of PBF or tissue metabolism using near infrared spectroscopy would probably give more useful information. Nevertheless, although these measurements have been validated against blood co-oximetry in human adults (25) and infants (26), they can only be made intermittently by a trained operator and are thus not appropriate for general clinical use. Further research is needed to find other better measures of peripheral perfusion and oxygenation which may be easily and continuously monitored, and which could this be more useful in a clinical setting.

\section{REFERENCES}

1. Earley A, Fayers P, Ng S, Shinebourne EA, de Swiet M 1980 Blood pressure in the first 6 weeks of life. Arch Dis Child 55:755-757

2. Kluckow M, Evans N 2001 Low systemic blood flow in the preterm infant. Semin Neonatol 6:75-84

3. Evans N, Kluckow M 1996 Early determinants of right and left ventricular output in ventilated preterm infants. Arch Dis Child Fetal Neonatal Ed 74:F88-F94 
4. Yoxall CW, Weindling AM 1998 Measurement of cerebral oxygen consumption in the human neonate using near infrared spectroscopy: cerebral oxygen consumption increases with advancing gestational age. Pediatr Res 44:283-290

5. van der Zee P, Cope M, Arridge SR, Essenpreis M, Potter LA, Edwards AD, Wyatt JS, McCormick DC, Roth SC, Reynolds EO, Deply DT 1992 Experimentally measured optical pathlengths for the adult head, calf and forearm and the head of the newborn infant as a function of inter optode spacing. Adv Exp Med Biol 316:143-153

6. Trevor Inglis GD, Dunster KR, Davies MW 2007 Establishing normal values of central venous pressure in very low birth weight infants. Physiol Meas 28:12831291

7. De Blasi RA, Ferrari M, Natali A, Conti G, Mega A, Gasparetto A 1994 Noninvasive measurement of forearm blood flow and oxygen consumption by near-infrared spectroscopy. J Appl Physiol 76:1388-1393

8. Yoxall CW, Weindling AM, Dawani NH, Peart I 1995 Measurement of cerebra venous oxyhemoglobin saturation in children by near-infrared spectroscopy and partial jugular venous occlusion. Pediatr Res 38:319-323

9. Devereux RB, Roman MJ 1995 Evaluation of cardiac and vascular structure by echocardiography and other noninvasive techniques. In: Laragh JH, Brenner, BM (eds) Hypertension: Pathophysiology, Diagnosis, Treatment. Raven Press, New York, pp 1969-1985

10. Walther FJ, Siassi B, King J, Wu PY 1986 Echocardiographic measurements in normal preterm and term neonates. Acta Paediatr Scand 75:563-568

11. Evans N, Kluckow M, Simmons M, Osborn D 2002 Which to measure, systemic or organ blood flow? Middle cerebral artery and superior vena cava flow in very preterm infants. Arch Dis Child Fetal Neonatal Ed 87:F181-F184

12. Kety SS, Schmidt CF 1948 The effects of altered arterial tensions of carbon dioxide and oxygen on cerebral blood flow and cerebral oxygen consumption of norma young men. J Clin Invest 27:484-492

13. Diji A, Greenfield AD 1960 The local effect of carbon dioxide on human blood vessels. Am Heart J 60:907-914
14. Diji A 1959 Local vasodilator action of carbon dioxide on blood vessels of the hand J Appl Physiol 14:414-416

15. Otis AB 1954 The work of breathing. Physiol Rev 34:449-458

16. Cain SM 1970 Increased oxygen uptake with passive hyperventilation of dogs J Appl Physiol 28:4-7

17. Springer RR, Clark DK, Lea AS, Solis RT 1979 Effects of changes in arterial carbon dioxide tension on oxygen consumption during cardiopulmonary bypass. Ches 75:549-554

18. Li J, Hoskote A, Hickey C, Stephens D, Bohn D, Holtby H, Van Arsdell G Redington AN, Adatia I 2005 Effect of carbon dioxide on systemic oxygenation, oxygen consumption, and blood lactate levels after bidirectional superior cavopulmonary anastomosis. Crit Care Med 33:984-989

19. Johnson PC 1978 Peripheral Circulation. Wiley, New York, pp 111-112

20. Bitterman H, Brod V, Weisz G, Kushnir D, Bitterman N 1996 Effects of oxygen on regional hemodynamics in hemorrhagic shock. Am J Physiol 271:H203-H211

21. Adir Y, Bitterman N, Katz E, Melamed Y, Bitterman H 1995 Salutary consequences of oxygen therapy on the long-term outcome of hemorrhagic shock in awake, unrestrained rats. Undersea Hyperb Med 22:23-30

22. Granger HJ, Goodman AH, Cook BH 1975 Metabolic models of microcirculatory regulation. Fed Proc 34:2025-2030

23. Granger DN, Hollwarth ME, Parks DA 1986 Ischemia-reperfusion injury: role of oxygen-derived free radicals. Acta Physiol Scand Suppl 548:47-63

24. Hassan IA, Wickramasinghe YA, Spencer SA 2003 Effect of limb cooling on peripheral and global oxygen consumption in neonates. Arch Dis Child Fetal Neonatal Ed 88:F139-F142

25. Yoxall CW, Weindling AM 1997 Measurement of venous oxyhaemoglobin saturation in the adult human forearm by near infrared spectroscopy with venous occlusion. Med Biol Eng Comput 35:331-336

26. Yoxall CW, Weindling AM 1996 The measurement of peripheral venous oxyhemoglobin saturation in newborn infants by near infrared spectroscopy with venous occlusion. Pediatr Res 39:1103-1106 